\title{
Acute pancreatitis: a rare presentation of systemic lupuserythematous (SLE) in paediatric age group
}

\author{
Parasher V. ${ }^{1}$, Dadhich G. ${ }^{2}$, Khatri R. ${ }^{3}$, Jhanwar P. ${ }^{4}$
}

${ }^{1}$ Dr. Vivek Parasher, Assistant Professor, ${ }^{2}$ Dr. Gaurav Dadhich, Senior Resident, ${ }^{3}$ Dr. Rahul Khatri, Senior Resident, Department of Paediatrics, Pacific Institute of Medical Sciences, Udaipur, ${ }^{4}$ Dr. Praveen Jhanwar, Assistant professor, Department of General Surgery, Pacific Institute of Medical Sciences, Udaipur

Address for Correspondence: Dr Praveen Jhanwar, M.Ch. Pediatric Surgery, Assistant Professor, Department of General Surgery, Pacific Institute of Medical Sciences, Udaipur, Residence: House No. 1043, Ghyan Nagar, Sector 4, Hiran Magari, E-mail: jhabbuu@gmail.com

\begin{abstract}
Key word: SLE, Acute pancreatitis, Steroid

\section{Introduction}

Acute pancreatitis is a rare but known presentation of SLE [1]. Incidence of acute pancreatitis ranges from $0.7 \%$ to $4 \%$ in SLE patients [2]. The pathogenesis of pancreatitis is not well understood till date, but it is presumed to be mediated by immune complex-induced microangitis [3]. So prompt diagnosis and immediate
\end{abstract}

Acute pancreatitis as an initial presentation of SLE in paediatric age group is extremely rare and needs high level of suspicion to make timely diagnosis as results may be fatal when not treated on time. treatment is the only tool for better prognosis. There are few reports on acute pancreatitis in paediatric lupus patients [4]. Here we are describing a case of 12 years old female child presented in emergency with acute abdomen, during work up diagnosed as lupus pancreatitis. Patient managed on steroid therapy and responded well.

\section{Case Report}

A 12 years old female child was admitted with acute pain abdomen and vomiting for last 6 days associated with rashes over face, trunk and extremities from last 1 month.

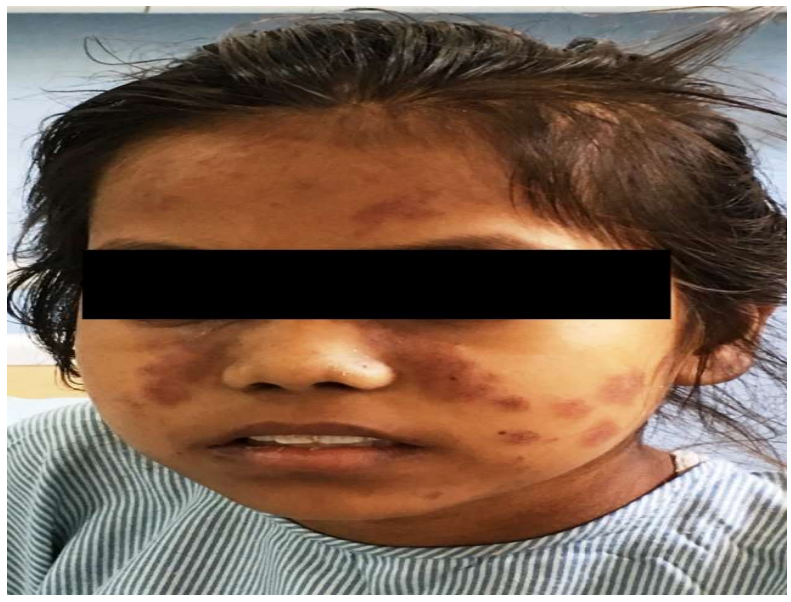

Fig-1: Discoidal rashes over face.

Manuscript received: $20^{\text {th }}$ December 2017

Reviewed: $28^{\text {th }}$ December 2017

Author Corrected: $05^{\text {th }}$ January 2018

Accepted for Publication: $12^{\text {th }}$ January 2018 
Editorial

On general examination, child was irritable, sick looking, dehydrated, febrile $\left(102^{0} \mathrm{~F}\right)$, tachycardic with normal blood pressure (BP- 104/68mmHg). She had pallor and discoidal rashes over face, trunk and extremities (Fig 1). Her abdominal examination revealed distended abdomen with tenderness in epigastric region with shifting dullness present on percussion.

At the time of admission investigation showed low $\mathrm{Hb}(7.5 \mathrm{gm})$ with severe leukopenia (Total WBC count- 2000/cmm), and normal platelets count $(1.851 / \mathrm{cmm})$. Liver enzymes were markedly raised (SGOT- $1400 \mathrm{IU} / \mathrm{L}, \mathrm{SGPT}-1023 \mathrm{IU} / \mathrm{L}$ ) with raised serum amylase (1560 U/L) and lipase (1693 U/L) level and low serum albumin level (2.4 gm \%). Her renal function test was normal. Ultrasonography of abdomen showed a bulky, hypo echoic pancreas with presence of free fluids in peritoneal cavity. Contrast enhanced computed tomography (CECT) abdomen confirmed diagnosis of acute pancreatitis (Fig 2).

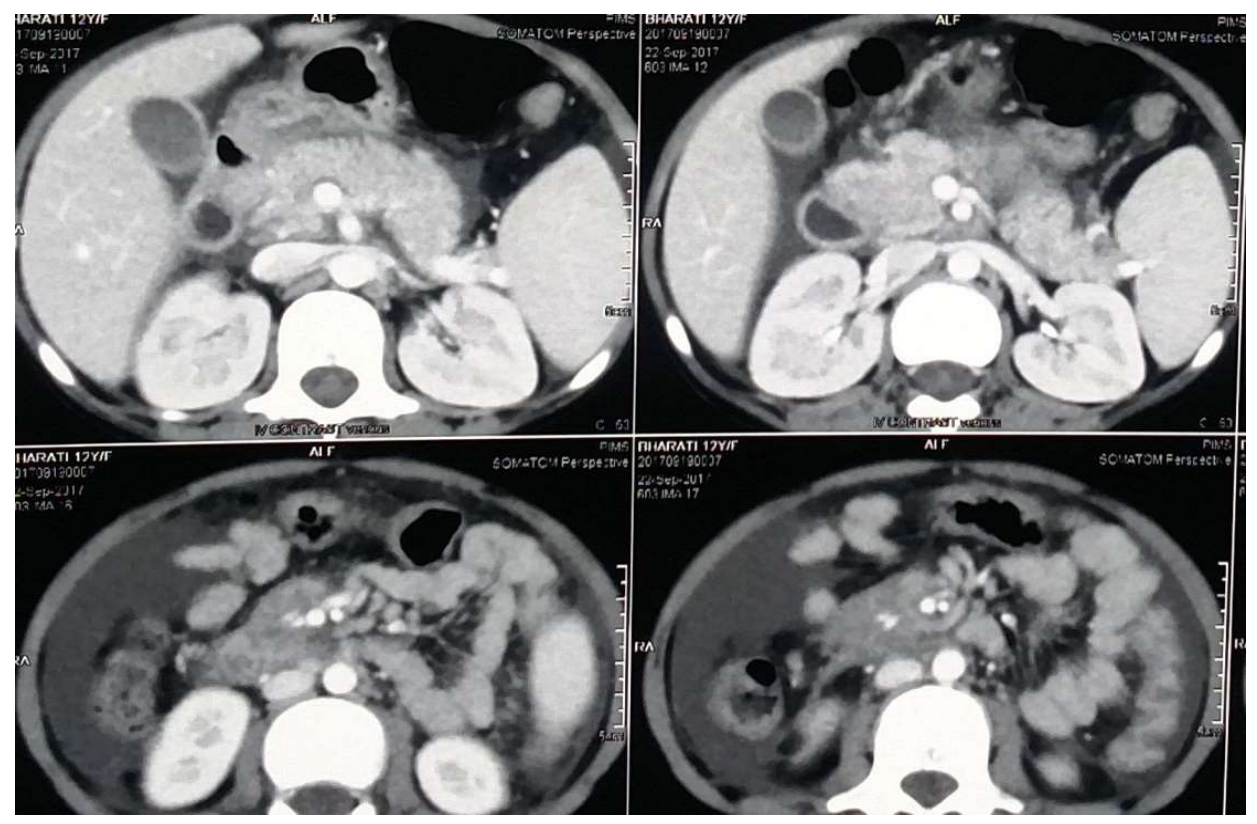

Fig-2: CECT Abdomen showing bulky pancreas with mild peripancreatic fluid collection suggestive of acute pancreatitis.

The connective tissue workup showed raised Anti-double-standard DNA antibody positivity (56.07) with elevated antinuclear antibody titre (>159 U/L) with low C3 level (75.70) supporting the diagnosis of SLE.

The child was put on intra-venous methylprednisolone $(30 \mathrm{mg} / \mathrm{kg} / \mathrm{day})$ with intravenous fluid for supportive management. She started improving on day 4 of admission, tolerating liquid diet. After 5 days, intra-venous steroid therapy was converted into oral one in form oftablet prednisolone $(2 \mathrm{mg} / \mathrm{kg}$ body weight). Child was discharged in stable condition after 18 days of admission. Rashes were subsided over the trunk and extremities but present over face at the time of discharge. Parents were advised to bring child in follow up after 7 days.

\section{Discussion}

Acute pancreatitis in association with SLE is exceedingly rare [4] especially in paediatric age group and till date less than 15 cases reported pancreatitis as an initial presentation of SLE [5]. A large study done by Campos et al [2], shows in their 26 years of study period, 11 patients had acute pancreatitis out of 263 patients of juvenile SLE, and out of which only 3 children have acute pancreatitis before SLE diagnosis. In this case also child presented to us with feature of acute pancreatitis which during evaluation diagnosed as SLE. The pathogenic mechanism of SLE-related pancreatitis seems to be multi-factorial [3] involving vascular damage, autoantibody production, abnormal cellular immune response, and drug toxicity but exact pathogenesis yet to be established. SLE has a protean manifestation and lupus pancreatitis has a very high mortality rate [6] (more than 60\%), so suspecting lupus pancreatitis early is the key of success in the management of these patients. As in this child CT 
Editorial

suggest diagnosis of acute pancreatitis and connective tissue evaluation confirms the diagnosis of SLE.

Renal, skin and joint involvement is commonly seen in lupus pancreatitis patients [7]. Even in Campos et al [2] study only one child doesn 't have renal involvement out of 11 patients who has lupus pancreatitis and luckily in our child renal and joint involvement was not there. Probably because of this also child had fast recovery.

Use of steroid treatment for lupus pancreatitis was controversial in past as it was seen that most cases of SLE pancreatitis occur in children with long standing SLE who have multi-organ involvement and are already on immunosuppressive therapy or steroid [8]. Now most of studies proved role of steroid therapy [9, 10]. Our patient was also responded well to steroid therapy and discharged on oral prednisolone.

\section{Conclusion}

our case is also supporting the existence of acute pancreatitis as an initial presentation of SLE although rare and also role of steroid therapy in the management. As well as if lupus pancreatitis is not associated with renal and joint involvement then we can expect fast recovery in those patients.

\section{Abbreviations}

SLE- Systemic Lupus Erythematous

BP- Blood Pressure

CECT- Contrast Enhanced Computed Tomography

Funding: Nil, Conflict of interest: None initiated, Perission from IRB: Yes

\section{References}

1. Pascual-Ramos V, Duarte-Rojo A, Villa AR, Hernández-Cruz B, Alarcón-Segovia D, Alcocer-Varela J, Robles-Díaz G. Systemic lupus erythematosus as a cause and prognostic factor of acute pancreatitis. J Rheumatol. 2004 Apr;31(4):707-12.

2. Campos LMA, Omori CH, Lotito APN, Jesus AA, Porta G, Silva CAA. Acute pancreatitis in juvenile systemic lupus erythematosus: a manifestation of macrophage activation syndrome?Lupus 2010; 19: 1654-1658. doi:10.1177/0961203310378863

3. Wang Q, Shen M, Leng X, Zeng X, Zhang F, Qian J. Prevalence, severity, and clinicalfeatures of acute and chronic pancreatitis in patients with systemic lupus erythematosus. Rheumatol Int. 2016 Oct;36(10):1413-9. doi: 10.1007/s00296-016-3526-z. Epub 2016 Jul 5.

4. Fan HC, Cheng SN, Hua YM et al., Systemic lupus erythematous-related acute pancreatitis: a case report. J Microbiol Immunol Infect 2003; 36: 212-214.

5. Bandyopadhyay D, Ganesan V, Bhar D et al., Acute pancreatitis- as a presenting manifestation of systemic lupus erythematosus. American Journal of Medical Case Reports 2015;3: 155-157.

6. Watts RA, Isenberg DA. Pancreatic disease in the autoimmune rheumatic disorders. Semis Arthritis Rheum 1989; 19: 158-65.

7. Gupta T, Singh A,Chauda R, Jain D, Aggarwal HK. Acute Pancreatitis: A Rare Presentation of Systemic Lupus Erythematosus. J Med Cases 2017; vol 8: 105107.

8. Marija S, Ivana B, Nina R, Dragan N, Zlatko B, Branislav J, Jelena P, Dusica S. Toxic epidermal necrolysis in a child with lupus-associated pancreatitis. Rheumatol Int. 2017 Jul;37(7):1221-1226. doi: 10.1007/s00296-017-3677-6. Epub 2017 Feb 26.

9. Perrin L, Giurgea I, Baudet-Bonneville V, Deschênes G, Bensman A, Ulinski T. Acute pancreatitis in paediatric systemiclupuserythematosus.ActaPaediatr. 20 06;95(1):121-4.doi:10.1080/08035250500325090

10. Limwattana S, Dissaneewate P, Kritsaneepaiboon S, Dendumrongsup T, Vachvanichsanong P. Systemic lupus erythematosus-related pancreatitis in children. ClinRheumatol. 2013 Jun;32(6):913-8. doi: 10.1007/s10067-013-2242-2. Epub 2013 May 15.

\section{How to cite this article?}

Acute pancreatitis: a rare presentation of systemic lupuserythematous (SLE) in paediatric age group Parasher V., Dadhich G., Khatri R., Jhanwar P. Int J Pediatr Res. 2018;5(1):43-45. doi:10.17511/ijpr.2018.i01.09. 